\title{
Study and Design Thailanna Style's Showcase
}

\author{
Nabhapol Mungpanklang ${ }^{1}$
}

\author{
Somchai Seviset $^{1 *}$
}

\section{Songwut Ekawutwongsa ${ }^{1}$}

\author{
${ }^{1}$ Department of Architectural Education and Design, \\ Faculty of industrial Education and Technology, \\ King Mongkut's Institute of Technology Ladkrabang, \\ Bangkok 10520, Thailand \\ ${ }^{*}$ Corresponding Author
}

Doi: 10.36941/mjss-2020-0003

\begin{abstract}
The purpose of this research is to study the Lanna art form, design showcase in Lanna art style and evaluate the satisfaction of those interested in buying a Lanna style showcase. The Lanna art forms that we studied are Lung Piang, Fat-Short, Flora patterns, Red color, Dark brown-black and gold patterns. Also the wood that has been using is Teak wood material, which is medium softwood. When analyzed together with the conceptual framework to design a showcase of Lanna art style, with experts and professionals join the evaluation of draft design 3 sets 9 drafts and eliminate to 1 draft only in order to use it as a prototype. Use descriptive statistics to analyze and summarize data. The research found that showcase in Lanna art style, draft $B$ which uses the design concept of Lanna art has overall result in the highest level $(\bar{X}=4.62$, S.D. $=$ 0.52). Then this draft is taking to produce the prototype and evaluate the satisfaction, the research found that satisfaction level in terms of conservation, inheritance, and pride of wisdom in art and cultural is at the highest level $(\bar{X}=4.41, S . D .=0.69)$, followed by beauty. And characteristics has satisfaction level at high level $(\bar{X}=4.25$, S.D. $=0.78)$. Safety, functional, structural and material satisfaction is at a high level $(\bar{X}=3.97$, S.D. $=0.70)$.
\end{abstract}

Keywords: Showcase, Thailanna Art, Design

\section{Introduction}

Lanna Kingdom is the Kingdom of Thai people in the past, located in the northern region of Thailand, which today is Chiang Mai, Lamphun, Lampang, Chiang Rai, Phayao, Phrae, Nan and Mae Hong Son. With the city of Chiang Mai as a capital city, having its own language, culture and traditions later being conquered until the end of the kingdom. During the prosperity period, Buddhism flourished, as shown in the construction of temples spread throughout Lanna in various villages, the temple was a community center as found in Chiang Mai city, and there are hundreds of temples. The amount of temples in the heyday left signs of many abandoned temples today. Progress in Buddhism has also created an institution in Buddhism which has Lanna cultural values, such as Wat Chet Yot, Chedi Luang Temple, Wat Phra Sing Wan Phan Tao, etc. The construction of many 
temples aside from showing prosperity in Buddhism also reflects the economic prosperity of Lanna during the prosperous era (Suraphon Damrikul, 2012).

Lanna furniture is blended with many nationals due to their involvement with various kingdoms, both as rulers and ruled, including being friends with various countries; the Lanna Fine Arts have an extensive network. The original furniture of Lanna was influenced by Hariphunchai art. And when Sukhothai and Lanka emerged, Lanna furniture developed to the greatest extent in the $21^{\text {st }}$ century until the end. Lanna is full of art that combines the same with many other kingdoms. Most of the furniture was created as a tribute to people with administrative or religious positions. The temple is considered a beautiful and diverse art. There are both external and internal fine arts, wood carvings in various designs, most of which are based on religious beliefs such as Flora, Lotus, Vines, Naga, or other animals. Houses of the general public the showcase is for value and importance things. Nowadays, various cultures have spread and influenced with Chiang Mai, the ideas, the environment and the traditional way of life of Lanna people have changed radically. Fine arts and furniture still remain as antiques that need to be preserved for posterity (Ong-On Tan Watcharaphan, 1997).

However, Lanna furniture at present is gradually disappeared according to time due to problems and some types of tools fade away from having modern technology to replace, however, the technology to replace has both advantages and disadvantages. According to the aforementioned problems, some communities that are still have occupation linked with furniture and still preserving Lanna art in order to promote the trend of conservatism. The researcher saw the increase in value and draw the uniqueness of Lanna art, which was a great city in the old days, to return to flourish in the art direction. "Industrial craft design". This concept is a product design that is created from a combination of local wisdom, culture and expertise in arts and crafts combined with creative thinking in design and industrial process to create a modern look to suit contemporary tastes with a cultural and spiritual of human which makes the design of industrial craft product to be unique, developing crafting skills, and being able to be sustainably self-reliant (Keativipak, K. Seviset, S and Eakwutvongsa, S. 2019) so as to benefit the economic development of the community in accordance with the national strategy, therefore have chosen to use teak that can be found in the teak planting project because it is of quality wood, suitable for furniture and also has been researched and tested for efficiency in Thailand. To provide basic information for the wood industry, the physical and mechanical properties and compositions of teak have been analyzed by many researchers. ( Seviset, S.; Piromgran, T.; Saributr, U.; Porncharoen, R.; Raerai, K.; Charoensettasilp, S. 2017 )

From the information mentioned above, the researcher as a furniture designer and is interested in preserving Lanna furniture to create a conservative trend and pull attention of people to interest in Lanna furniture, value of Lanna art, identity creation and identity for the community and support the community to benefit.

\section{Objectives}

1. Study the showcase of Lanna art style

2. Design showcase in Lanna art style

3. Evaluate the satisfaction of those interested in buying the showcase towards the developed Lanna art furniture

\section{Methodology}

Study and design of showcase in Lanna art style. The researcher has the following research methods:

\subsection{The sampling group used purposive sampling.}

The group of informants used in the study of the showcase of Lanna art form is the group of data no. 1: 3 Lanna furniture experts. The group of data no. 2: 3 the speakers about Lanna art and culture. The 
group of data no. 3: 3 Lanna furniture makers.

The group of informants used in designing the showcase of Lanna art style is 3 experts in Lanna furniture design, 3 Lanna art experts and 3 experts in Lanna furniture production, totaling 9 people.

The informational group used to assess the satisfaction of those interested in buying to showcase of developed Lanna art form is 30 persons who interested in buying using Lanna furniture or those who choose to buy products at the end.

\subsection{Data sources}

Primary data is the interviewing and observation of the informants: 3 experts in Lanna furniture, 3 speakers of Lanna art and culture, and 3 Lanna furniture craftsmen.

Secondary data, the researcher has studied and researched the data in both similar parts and in the related documents, textbooks and research papers including from various sources from government agencies and from online sources Related to the showcase of Lanna art styles

\subsection{Research tools}

The unstructured interview about the showcase in Lanna art form, namely the interview of experts, speakers about Lanna and the Lanna furniture maker by using the recording form, images and sound.

Evaluation form for opinions of Lanna furniture design, namely the evaluation form used by experts in Lanna furniture design, Lanna art expert and experts in Lanna furniture production.

The evaluation form for those who are interested in buying the developed Lanna art showcase, consisting of Satisfaction assessment form of interested people and people who choose to buy furniture at Thawai community of 30 people and a prototype model showcase of the developed Lanna art style.

\subsection{Data Analysis}

In data analysis, the researcher uses statistical methods to analyze information about the initial opinions about the showcase style of Lanna art style in interview and observation form, short answer form and long answer form. Using descriptive statistical methods, summarizing information, finding guidelines and basic information, dividing issues into categories and perform data analysis.

Data analysis, the researcher uses statistical data to analyze the design to find a suitable way for designing a showcase of Lanna art style which analyzes about respondents. The question is about personal information and the design of the showcase in Lanna art style according to the conceptual framework of the design. Present data by finding percentage taking the data to calculate and analyze the statistical values by using mean $(\overline{\mathrm{x}})$, standard deviation (S.D.).

Data analysis of satisfaction evaluation of those who are interested in buying a showcase of the developed Lanna art form. The question is about personal information. And the satisfaction of those interested in buying towards the showcase of the developed Lanna art style. Using the statistical data to analyze satisfaction, present the data by finding the percentage taking the data to calculate and analyze the statistical values by using mean $(\overline{\mathrm{x}})$, standard deviation (S.D.). 


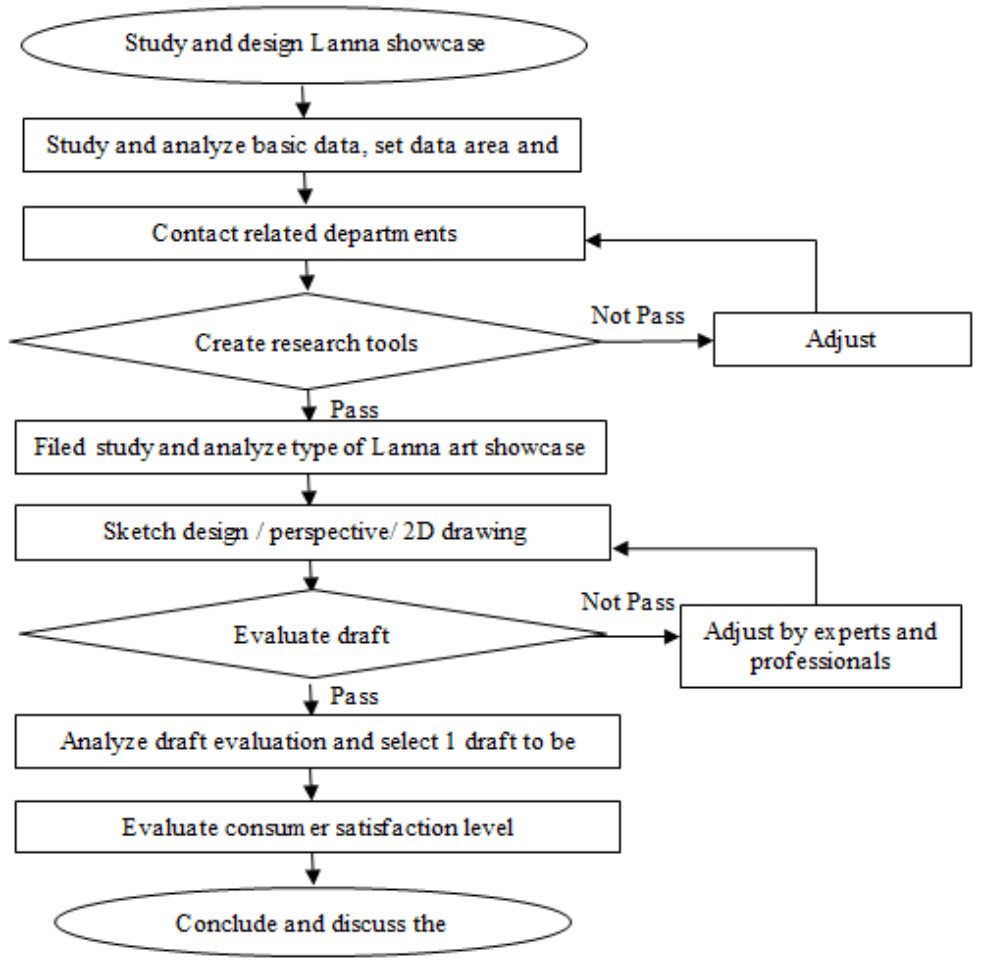

Flow Chart 1: Research Process

\section{Research Result}

The results of the study about the study of the Lanna art display cabinet model found that the outstanding features used in the design work include the shape of Lung Piang or the short-fat castle according to the art of inheritance. The unique pattern is the Phlueksa pattern, which is the pattern that is widely used in Lanna art. The color tone obtained from nature is a pair of colors, reflecting the unique characteristics of the local area that combines nature with the creation of the million people. Rice fields perfectly, including vermilion with red color, Ruk rubber that gives dark brown - black and golden colors for mostly used is teak materials. The production will use wood that can be found in the general area. Most of them are medium softwood. This type of wood is commonly used to make cabinets and work that needs beautiful resolution.

Results of the Lanna art showcase design according to the study of the information of the Lanna art showcase, the B format which uses the design concept of Lanna art. The overall suitable level was highest $(=4.62$, S.D $=0.52)$. When considering each item, it was found that showcase in Lanna art style, can preserve Lanna art coming in 1st, followed by contemporary beauty and beautiful according to the Lanna art style, suitable for gilding work, convenient to use, have the right proportions and are safe to use respectively as shown in Table 1. 
Table 1: The results of the analysis of the design of 3 types of Lanna art showcase by experts in Lanna furniture design, Lanna art experts and Lanna furniture maker totaling 9 persons.

\begin{tabular}{|c|c|c|c|c|c|c|c|c|c|}
\hline \multirow{3}{*}{ Item } & \multicolumn{9}{|c|}{ Opinion } \\
\hline & & & & & & & & & \\
\hline & $\overline{\bar{X}}$ & S.D & Level & $\overline{\bar{X}}$ & S.D & Level & $\bar{X}$ & S.D & Level \\
\hline 1. Lanna showcase has Lanna art aesthetic & 3.67 & 0.47 & High & 4.69 & 0.42 & Highest & 3.33 & 0.47 & Medium \\
\hline $\begin{array}{l}\text { 2. Level of contemporary art in Lanna } \\
\text { showcase }\end{array}$ & 3.67 & 0.47 & High & 4.78 & 0.42 & Highest & 3.67 & 0.47 & High \\
\hline $\begin{array}{l}\text { 3. Lanna showcase suitable with engrave } \\
\text { golden work }\end{array}$ & 2.67 & 0.94 & Medium & 4.67 & 0.67 & Highest & 2.67 & 0.94 & Medium \\
\hline 4. Lann showcase is safe to use & 2.33 & 0.47 & Low & 4.33 & 0.47 & High & 1.67 & 0.94 & Low \\
\hline 5. Lanna showcase is convenient to use & 3.00 & 0.82 & Medium & 4.55 & 0.94 & Highest & 2.33 & 0.47 & Low \\
\hline 6. Lanna showcase is in right proportion & 3.33 & 0.47 & Medium & 4.44 & 0.45 & High & 2.33 & 0.47 & Low \\
\hline 7. Lanna showcase can conserve Lanna art & 3.00 & 0.00 & Medium & 4.89 & 0.31 & Highest & 2.67 & 0.47 & Medium \\
\hline Total & 3.09 & 0.52 & Medium & 4.62 & 0.52 & Highest & 2.66 & 0.60 & Medium \\
\hline
\end{tabular}

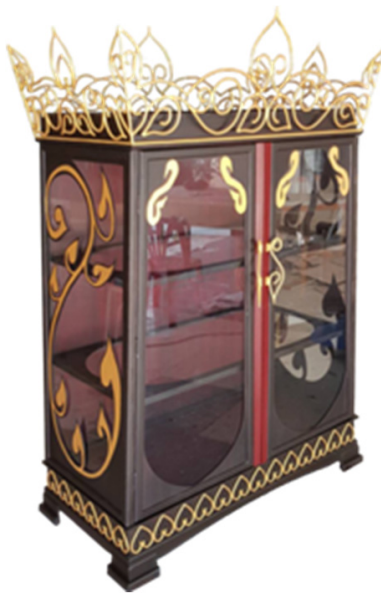

Fig. 1: Lanna showcase that has been developed to evaluate buyer satisfaction Source: Nabhapol Mungpanklang (2019)

Summary of the evaluation of satisfaction of those interested in buying to showcase the Lanna art form developed by 30consumers, it is found that conservation, inheritance, and pride in the wisdom, artistic heritage and culture are Highest satisfaction with an average of $=4.41$, followed by aesthetic and characteristics with satisfaction level at a high level, with an average of $=4.25$. And safety, functional, structural and material satisfaction is at a high level, with an average of $=3.97$ as shown in Table 2. 
Table 2: Summary of the evaluation of satisfaction of those interested in buying to showcase the Lanna art form developed by 30 consumers.

\begin{tabular}{|c|c|c|c|}
\hline \multirow{2}{*}{ Item } & \multicolumn{3}{|c|}{ Buyer satisfaction level } \\
\hline & $\overline{\mathrm{X}}$ & S.D. & Level \\
\hline \multicolumn{4}{|c|}{ Conservation, inheritance, and pride in the wisdom, artistic heritage and culture } \\
\hline 1. In which level Lanna showcase can represent Lanna art? & 4.60 & 0.62 & Highest \\
\hline 2. In which level Lanna showcase can preserve Lanna art? & 4.47 & 0.65 & Highest \\
\hline 3. In which level Lanna showcase can make pride in Lanna art? & 4.36 & 0.76 & High \\
\hline 4. In which level Lanna showcase can create conservative trend in Lanna art? & 4.20 & 0.75 & High \\
\hline Total & 4.41 & 0.69 & Highest \\
\hline \multicolumn{4}{|l|}{ Aesthetic and characteristics } \\
\hline 5. In which level Lanna showcase show Lanna art aesthetic? & 4.17 & 0.86 & High \\
\hline 6. In which level Lanna showcase show contemporary art aesthetic? & 4.21 & 0.70 & High \\
\hline Total & 4.25 & 0.78 & High \\
\hline \multicolumn{4}{|l|}{ Safety, functional, structural and material } \\
\hline 7. Lanna showcase is safe to use & 4.10 & 0.61 & High \\
\hline 8. Structure of Lanna showcase is steady & 3.93 & 0.57 & High \\
\hline 9. Lanna showcase can used to showcase any type of item & 3.81 & 0.76 & High \\
\hline 10. In which level Lanna showcase is proportional? & 4.13 & 0.88 & High \\
\hline Total & 3.97 & 0.70 & High \\
\hline
\end{tabular}

\section{Discussion and Conclusions}

\subsection{Discussion of the results of the study of the showcase of Lanna art form.}

In order to provide the information that is studied for the purpose of the research well, use the conceptual framework. The direction of art and culture development of the National Culture Master Plan (2007 - 2016: 58) consists of preserving, inheriting and creating pride in the wisdom, artistic heritage, culture, art and culture based on local cultural diversity. And from the study, it is found that the style of the Lanna showcase and the pattern is created by the work of the creator's imagination. The outstanding feature of showcase is the size called "fat-short" according to the artistry that has been in the past. The unique pattern that can be expressed in the Lanna style is the Phan Phansa pattern which is the pattern that is widely used in Lanna art. The problem of the Lanna style showcase in the present is that it is gradually disappeared due to various problems. In order to effectively preserve Lanna art, respond to current consumer behavior with designs based on Udomsak Sariputr furniture design principles (2007). The researcher has selected 7 topics to suit the research, consisting of 1 . Usable function 2. Safety 3. Material 4. Structure 5. Convenience of use 6. Beauty and unique characteristics 7. Production methods and principles of product development, handicraft by Wiwatchai Bunyaphak (1989), with 3 important topics, consisting of 1 . Using local materials and creating value for local materials 2 . Local identity and 3 . The freshness of products.

\subsection{Discuss the analysis results of Lanna art showcase design.}

Analysis result of Lanna art style showcase design analyze from the questionnaire interview and observation forms in which the researcher analyze according to the conceptual framework, the objective is the direction of art and culture development of the National Culture Master Plan (2007 2016: 58) in order to use the information to design and design the showcase of Lanna art style in 3 types according to the furniture design principles of Udomsak Sariputr (2007) and the principle of product development of Wiwatchai Bunyaphak (1989) to find that Type B is the type that expert in design Lanna art and a total of 9 production experts assessed at high-highest level. The researcher 
therefore recommends Type B to improve according to the recommendations. Found that the pattern, size, proportion and weight should be reduced, including the excess decorative parts outside the cabinet, which may cause the accidence to the users, should choose patterns that are prominent in Lanna art to make Lanna art more clear and should consider the use of materials that are easy to find and is durable.

5.3 Discuss the analysis results of the satisfaction evaluation of buyers interested in the showcase of Lanna art that was developed.

The results of the evaluation of satisfaction of those interested in buying the developed Lanna art showcase found that the result of the analysis of opinions on conservation, inheritance and creating pride in the wisdom, artistic heritage and culture is in the highest level. And aesthetic and characteristics is in highest level. The result of the analysis of the opinions of safety, function, structure and materials is at the high level as the outstanding Lanna art showcase makes it memorable due to the integration of the Lanna period with modern design. Resulting in designs that combine the art of both eras together in accordance with the furniture design principles of Udomsak Sariputr (2007) and the principles of product development Wiwatchai Bunyaphak (1989).

\section{Suggestion}

- The analysis results of the Lanna art showcase design can be used in the design of Lanna furniture to be Lanna furniture sets with the same concept, such as a table, bed, or sofa set.

- The developed furniture should consider the repair, maintenance, assembly and transportation in accordance with the current technology.

- Developing production to be able to be disassembled by yourself for distribution by logistic system in the industrial sector, should consider the Lanna identity along with production, because some technology may make the Lanna art disappear.

\section{References}

Akiko Nakatani. (2011). Analysis of Japanese and finnish furniture design: A consideration for product identity and the relativity of industrial development and cultural context. Industrial Design. Faculty of Art and Design. University of Lapland

Bella Martin and Bruce Hanington. (2018). The Pocket Universal Methods of Design. China. Rockport Publishers Inc.

Children of Baan Thawai. Glorify the wood carving of Baan Thawai, Chedchu Sala Mai Keasalak Baan Thawai.

Keativipak, K. Seviset, S and Eakwutvongsa, S. (2019) Study of Paradigm and Theories that are Factors Influencing the Development and Creation of Industrial Crafts Products in Thailand, Mediterranean Journal of Social Sciences, Vol 10 No 5 p. 115-121.

Komsun Suriya, Siripon Srisuchart, and Pitsamai Awakulpanit. (2008). Contemporary Lanna souvenir development. $1^{\text {st }}$ publishing Chiangmai:S.T. Film and Plate

Ministry of Culture. (2016). Original craftsmanship. [Online]. Available: https://www.m-culture.go.th /mculture_th6o/ebook/Bo359/\#p=1 searched on (April 9, 2018).

Nair, K.R.; Mukerji, H.K. A. (1960).statistical study of the variability of physical and mechanical properties of Tectonagrandis (Teak) grown at di erent localities of India and Burma and the e_ects of the variability on the choice of the sampling plan. Indian For. Rec. 1, 49.

Natthaphon Thoewpanich. (2013). Design of Art Numbers, Environment, Lanna Identity. Master of Arts, Fine Arts Program. Post Graduate College. Silpakorn University

Nuannoi Wongwong. (1996). Design principles. Bangkok: Chulalongkorn University Press.

Office of Small and Medium Enterprises Promotion. (2008). Marketing strategy in foreign countries. [Online]. Available:http://www.sme.go.th/en/download.php?modulekey=224. Retrieved (April 9, 2018).

Ong Oran Watcharaphan. (1997). The evolution of Thai houseware. Bangkok: Saha Pracha Panich.

Pawinee Kanchana. (2011). Marketing Principles. Bangkok: Top Publishing Company Limited 
Phichai Leiphatphibiboon. (1999). What is QED. For Quality Journal.

Phorn Sanongwong Singthong. (2007). Research methods in product design. Bangkok: The Publisher of Chulalongkorn University

Ponneth, D.; Vasu, A.E.; Easwaran, J.C.; Mohandass, A.; Chauhan, S.S. (2014). Destructive and non-destructive evaluation of seven hardwoods and analysis of data correlation. Holzforschung. 68, 951-956.

Poomsak Sukkaew. (2014). Study and Design of Traditional Thai Houseware from Old Wood for Professional Training. Master of Industrial Education, Industrial Product Design Technology Program. King Mongkut's Institute of Technology Ladkrabang

Rizanti, D.E.; Darmawan,W.; George, B.; Merlin, A.; Dumarcay, S.; Chapuis, H.; Gérardin, C.; Gelhaye, E.; Raharivelomanana, P.; Sari, R.K. (2018). Comparison of teak wood properties according to forest management: Short versus long rotation. Ann. For. Sci. 75, 39.

Royal Academy. (1999). Satisfaction. Bangkok: Bureau of Film and Music.

Saraswati Ongsakul. (2016). Examining evidence of Lanna history. 1st edition, Chiang Mai: With In Design.

Sathit Chiangthong. (1992). Imagination from Lanna architectural patterns. Bachelor of Arts. Department of Graphic Arts And sculpture. Faculty of Fine Arts, Chiang Mai University.

Seviset, S.; Piromgran, T.; Saributr, U.; Porncharoen, R.; Raerai, K.; Charoensettasilp, S. (2017). Mechanical Property of 9 Years Old Thinning of Teak Plantation in Thailand. MATEC Web Conf. 95, 03004.

Sirichai Kanchanawati, Thawiwat Pitiyanon and Direk Srisuko. (2016). Choosing the right statistics for research. 7th edition Bangkok: The Publisher of Chulalongkorn University

Suraphon Damrikul. (1996). Lai Kham Lanna. 1st edition. Bangkok: Dan Sutthakan.

Suraphon Damrikul. (2012). Lanna Land. 2nd edition, Bangkok: Dan Sutthakan printing.

Thawatchanon Sippapakul. (2005). Medicine and Mechanical Anatomy. 2nd edition Bangkok: Drawing Art Co., Ltd. Udomsak Saributr. (2007). Furniture designs. Bangkok: O Printing House

Valerie L. Winslow. (2009). Classic Human Anatomy. First printing China : Watson - Guptill Publications / Random House, Inc., New York

Wannee Sahasomchok. (2006). Principles of furniture design. Bangkok: Technology Promotion Association

Watana Watthanaphan, Dobphathana Watthanaphan, and Samart Si Jumnong. (2001). Lanna Folk Art: Change for Existence. 1st edition, Chiang Mai: With In Design.

Wichian Ketasingha. (1987). Principles of creating and analyzing research instruments. Bangkok: Thai Wattana Panich

Wittayaphon Withun. (2007). Marking line drawing words with snazzy words. Chiang Mai: Pim Nana. 